\title{
Primary Hepatic Angiosarcoma: A Rare Liver Malignancy - Varying Manifestations but Grave Prognosis
}

\author{
Natthapat Rujeerapaiboon Panu Wetwittayakhlang \\ Gastroenterology and Hepatology Unit, Division of Internal Medicine, Faculty of Medicine, \\ Prince of Songkla University, Songkhla, Thailand
}

\section{Keywords}

Primary hepatic angiosarcoma $\cdot$ Hepatic angiosarcoma $\cdot$ Intra-tumoral hemorrhage

\begin{abstract}
Primary hepatic angiosarcoma (PHA) is a rare mesenchymal liver tumor, accounting for $0.1-2 \%$ of primary liver malignancies. The clinical presentations of PHA are variable, from asymptomatic to liver failure or complicated with tumor rupture. The diagnosis of PHA is difficult due to the lack of specific clinical manifestation and investigation results, which can be confused with other liver tumors resulting in late diagnosis. However, there is currently a paucity of effective therapeutic approaches. We advocate early diagnosis with radiological imaging and histopathology because most of them are diagnosed in late-stage and carry a grave prognosis. Surgical resection remains the mainstay of treatment, which can significantly prolong survival. Chemotherapy, including transarterial chemoembolization, is an option for palliative treatment. Unfortunately, molecular treatment has limited efficacy and liver transplantation is also not recommended due to high rate of recurrence. We present a case series of four patients with biopsy-proven PHA which had distinct presentations and clinical courses.
\end{abstract}




\section{Case Reports in Gastroenterology} \begin{tabular}{l|l}
\hline Case Rep Gastroenterol 2020;14:137-149 \\
\hline DOI: 10.1159/000506928 & $\begin{array}{l}\text { @ 2020 The Author(s). Published by S. Karger AG, Basel } \\
\text { www.karger.com/crg }\end{array}$
\end{tabular}

Rujeerapaiboon and Wetwittayakhlang: Primary Hepatic Angiosarcoma: Varying Manifestations but Grave Prognosis

\section{Introduction}

Primary hepatic angiosarcoma (PHA) is a rare hepatic tumor, originating from endothelial and fibroblastic tissue, primarily made up of vessels and composed of abundant vasculature. It represents only $0.1-2 \%$ of all primary liver malignancies [1]. PHA commonly occurs in ages from 60 to 70 years. The clinical presentations are variable, from asymptomatic to liver failure; most patients have nonspecific symptoms at initial presentation that usually mimic other chronic liver diseases and are difficult to distinguish from other liver malignancies, resulting in late diagnosis and delayed treatment. These symptoms include abdominal pain, fatigue, weight loss, jaundice, and anorexia. Physical examination can reveal hepatomegaly, ascites, or jaundice [2]. Few patients present with hemoperitoneum secondary to tumor rupture, which was reported in $17-27 \%$ of cases [3, 4]. The differential diagnosis of PHA are hepatocellular carcinoma, cholangiocarcinoma, metastatic carcinoma of liver, and hepatic hemangioma. Furthermore, there is a lack of specific laboratory findings for diagnosis of PHA, include liver function test or tumor markers. Imaging study and pathological features remain the key to aid diagnosis. On computed tomography (CT), the dominant tumors usually show heterogenous enhancement, suggesting central necrosis or hemorrhage and delayed progressive enhancement [5-7]. Pathologically, PHA is composed of pleomorphic atypical mesenchymal cells with elongated nuclei, and the tumor exhibits its own disorganized anastomotic vascular channels. The areas of necrosis and hemorrhage are commonly reported in histological findings [3], when more specific immunohistochemical markers for PHA including ERG expression, CD34, CD31, and factor VIII can lead to definite diagnosis [8]. Unfortunately, PHA is associated with grave prognosis. Surgical resection remains a curative treatment; however, it is difficult to perform because $80 \%$ of patients have advanced stage at diagnosis. Chemotherapy and transcatheter arterial chemoembolization (TACE) are considered a palliative treatment. Liver transplant is not recommended due to a high rate of recurrence and rapid progression of tumor with survival after liver transplant less than 7 months. The majority of patients have medial survival less than 1 year, even after receiving treatment. The common causes of death are liver failure and hemoperitoneum from spontaneous tumor rupture $[4,9,10]$.

There has been a paucity of data and significant challenges regarding the diagnosis, treatment, and prognosis of this tumor. Many physicians remain unaccustomed to the clinical features of PHA. We present the cases of four patients with biopsy-proven PHA, which had distinct presentations and clinical courses.

\section{Case Presentation}

\section{Case 1}

An 81-year-old man was admitted due to massive upper gastrointestinal hemorrhage for $2 \mathrm{~h}$. He had epigastric pain and early satiety for 3 weeks. His past medical history was unremarkable except for heavy alcohol drinking, 1-2 bottles a day for over 30 years. He denied a history of exposure to thorotrast or vinyl chloride. Physical examination revealed mildly pale, icteric sclerae, hepatomegaly with a liver span of $14 \mathrm{~cm}$, parotid gland enlargement and palmar erythema. Other examinations were unremarkable. Laboratory investigations on admission showed white blood cell (WBC) count 6,210/dL, hemoglobin (Hb) $5.8 \mathrm{~g} / \mathrm{dL}$, platelet count 
$283 \times 10^{3} / \mathrm{dL}$, aspartate transaminase (AST) $116 \mathrm{U} / \mathrm{L}$, alanine aminotransferase (ALT) $73 \mathrm{U} / \mathrm{L}$, alkaline phosphatase (ALP) $192 \mathrm{U} / \mathrm{L}$, albumin $2.7 \mathrm{~g} \%$, total bilirubin (TB) $5.74 \mathrm{mg} \%$, direct bilirubin (DB) $5.3 \mathrm{mg} \%$, prothrombin time (PT) $16.2 \mathrm{~s}$ (control 12.4), and international normalized ratio (INR) 1.23; serum alpha-fetoprotein (AFP) was within normal range.

Esophagogastroduodenoscopy was performed and revealed a 3-cm large ulcer with elevated border and necrotic tissue in the antrum of stomach; no varix was seen. The tissue biopsy was performed to exclude malignant ulcer. Liver ultrasonography revealed a cirrhotic liver and diffused multiple echogenic nodules size 7-9 $\mathrm{mm}$ in both lobes with a large echogenic mass $3.3 \mathrm{~cm}$ in size with a halo. A further CT scan demonstrated multiple large infiltrative masses with few arterial enhancements, no venous washout, size 1-4 cm in both lobes, osteolytic foci at the thoracic spine level T10 and T11, and small subpleural nodule at the right lower lung. Liver biopsy was performed for definite diagnosis. The specimen consisted of a few pieces of gray tan irregular soft tissue and disclosed the angiosarcoma; immunohistochemical study showed positive staining for CD34 and factor VIII. The specimen of gastric ulcer biopsy also revealed metastasis of angiosarcoma.

He was treated with a paclitaxel dose of $175 \mathrm{mg} / \mathrm{m}^{2}$. Unfortunately, 5 days after receiving chemotherapy, he developed febrile neutropenia with septic shock. His relatives refused further treatment and invasive procedures, and he died in the following days.

Case 2

A 55-year-old woman with a medical history of type 2 diabetes mellitus, presented with right upper abdominal pain and significant weight loss for 5 months, and progressive jaundice for 2 months. She denied a history of carcinogen exposure. Physical examination showed hepatomegaly $4 \mathrm{~cm}$ below the right costal margin with a liver span of $15 \mathrm{~cm}$. Liver examination described a rubbery to firm consistency, blunt edge, and smooth surface. Other findings were unremarkable except mild icteric sclerae. The complete blood count revealed: WBC 9,820/dL, $\mathrm{Hb} 12.0 \mathrm{~g} / \mathrm{dL}$, and platelet count $98 \times 10^{3} / \mathrm{dL}$. The liver function test showed: AST $44 \mathrm{U} / \mathrm{L}, \mathrm{ALT}$ $20 \mathrm{U} / \mathrm{L}$, ALP $449 \mathrm{U} / \mathrm{L}$, TB $3.81 \mathrm{mg} \%$, DB $2.57 \mathrm{mg} \%$. The serum AFP was $2.16 \mathrm{ng} / \mathrm{mL}$ (normal $<7 \mathrm{mg} / \mathrm{mL}$ ).

Multiphase CT scan demonstrated diffused multiple arterial enhancing infiltrating nodules varying in size, scattered throughout the entire liver, with ascites and mesenteric fat reticulation suspicious of carcinomatosis peritonei.

Laparoscopic liver biopsy was performed for diagnosis, and the specimen consisted of a piece of light brown irregular soft tissue. Histopathological findings showed the presence of diffused proliferation of abnormal small vessels with diffused hemorrhage. The abnormal vessels showed enlarged endothelial cells with nuclear atypia. Immunohistochemical study showed positive staining for CD34 and factor VIII in the endothelial cells. Histopathological study was consistent with PHA (Fig. 1).

She received a total of five cycles of paclitaxel with a $20 \%$ dose reduction. The following posttreatment CT scans showed progression of the disease with peritoneal metastasis, and she later decided to stop treatment. She survived for 19 months and 14 months after symptom onset and treatment initiation, respectively. 


\section{Case Reports in Gastroenterology} \begin{tabular}{l|l}
\hline Case Rep Gastroenterol 2020;14:137-149 \\
\hline DOI: 10.1159/000506928 & $\begin{array}{l}\text { @ 2020 The Author(s). Published by S. Karger AG, Basel } \\
\text { www.karger.com/crg }\end{array}$
\end{tabular}

Rujeerapaiboon and Wetwittayakhlang: Primary Hepatic Angiosarcoma: Varying Manifestations but Grave Prognosis

Case 3

A 47-year-old woman without past medical history was admitted due to acute right upper abdominal pain for $8 \mathrm{~h}$ and syncope prior to admission. She had a history of taking oral contraceptive pills 4-6 months per year, for 7 years. Physical examination revealed vital signs: BP $100 / 60 \mathrm{~mm} \mathrm{Hg}$, pulse rate $115 / \mathrm{min}$. Her body mass index was $33.6 \mathrm{~kg} / \mathrm{m}^{2}$. Abdomen examination showed marked tenderness at the right upper quadrant; the liver was palpated $8 \mathrm{~cm}$ below the costal margin with a liver span of $20 \mathrm{~cm}$ with mild tenderness, no splenomegaly, and no shifting dullness.

Laboratory investigations showed: WBC count 8,200/dL, Hb $7.4 \mathrm{~g} / \mathrm{dL}$, and platelet count $592 \times 10^{3} / \mathrm{dL}$, AST 34 U/L, ALT 23 U/L, ALP 335 U/L, TB 1.22 mg\%, DB 0.73 mg\%; coagulogram was in normal limit, AFP was $2.72 \mathrm{ng} / \mathrm{mL}$.

The emergency CT scan revealed acute rupture of liver tumor by evidence of acute clot and acute hematoma. She was provisionally diagnosed with ruptured hepatic adenoma and underwent emergency hepatic embolization. The angiography finding revealed a large hepatic mass at the anterior aspect of the right hepatic lobe, receiving arterial supply from the anterior branch of the right branch of the hepatic artery. Eventually, embolization was performed to stop bleeding. The scheduled CT scan 2 weeks after embolization showed a larger diameter of hemorrhagic mass from 20.7 to $23.0 \mathrm{~cm}$, lysed perihepatic hematoma, without distance metastasis (Fig. 2).

Four weeks after embolization, she underwent extended right hepatectomy with wedge diaphragm and primary repair. The operation demonstrated a huge liver mass with intratumoral hemorrhage, displaced IVC, and mediastinum. The specimen consisted of a liver tumor size $28 \times 20 \times 14 \mathrm{~cm}$ and weighing 2,300 g. The tumor appeared to be a light-brownish rubbery mass with a massive hemorrhage. The histopathological finding was compatible with angiosarcoma (French system grade III) and free tumor margin. The immunochemical staining was positive for CD34 and factor VIII, consistent with PHA (Fig. 3).

The follow-up CT scan was performed after surgery, and it showed multiple new nodules about $0.5-2 \mathrm{~cm}$ in the left lobe liver, a heterogenous enhancing mass size $3.7 \mathrm{~cm}$ in the right subdiaphragmatic space; peritoneal thickening was also noted. Thus, the physicians planned to treat her with chemotherapy, doxorubicin. However, she refused chemotherapy treatment because of her poor clinical condition, and she passed away 4 months later.

Case 4

A 69-year-old previously heathy woman presented with left upper quadrant pain for 2 months. She described her intermittent colicky abdominal pain, each attack lasting $10 \mathrm{~min}$. She also noticed a weight loss of $3 \mathrm{~kg}$ in a week. Physical examination showed palpated liver $4 \mathrm{~cm}$ below the right costal margin and $6 \mathrm{~cm}$ below the xyphoid; the surface of the liver appeared to be lobulated with firm consistency; no hepatic bruit was heard.

The laboratory investigation showed: WBC count 5,080/dL, Hb $10.5 \mathrm{~g} / \mathrm{dL}$, and platelet count $99 \times 10^{3} / \mathrm{dL}$, AST $84 \mathrm{U} / \mathrm{L}$, ALT $33 \mathrm{U} / \mathrm{L}$, ALP $187 \mathrm{U} / \mathrm{L}$, TB $2.47 \mathrm{mg} \%$, DB 1.48 mg\%, PT $20 \mathrm{~s}$ and INR 1.89. The serum tumor markers included AFP, CEA, and CA 19-9 and were within normal limits. The scheduled CT scan demonstrated numerous masses, and multiple nodules size 1-9 $\mathrm{cm}$ across the entire liver, an osteoblastic lesion at $L 4$ vertebrae, multiple small nodules $2-8 \mathrm{~mm}$ in size at both lungs with surrounding ground glass, which is typical for hemorrhage (Fig. 4). 


\section{Case Reports in Gastroenterology} \begin{tabular}{l|l}
\hline Case Rep Gastroenterol 2020;14:137-149 \\
\hline DOI: 10.1159/000506928 & $\begin{array}{l}\text { @ 2020 The Author(s). Published by S. Karger AG, Basel } \\
\text { www.karger.com/crg }\end{array}$
\end{tabular}

Rujeerapaiboon and Wetwittayakhlang: Primary Hepatic Angiosarcoma: Varying Manifestations but Grave Prognosis

For a definite diagnosis, she underwent real-time sonographic guidance percutaneous tumor biopsy. The specimen consisted of light brown soft tissue. The histopathological finding revealed a malignant vascular tumor, immunochemistry staining positive for CD 34 and factor VIII. These findings are consistent with angiosarcoma.

The patient had planned to have chemotherapy. Unfortunately, 2 weeks after diagnosis, she was admitted to the hospital due to severe abdominal pain. Investigations revealed a ruptured tumor, evidence of disseminated intravascular coagulopathy, and liver failure. Thus, she denied invasive therapy and passed away 1 week later.

The clinical manifestation, tumor feature, and treatment outcome of the four patients are summarized in Table 1.

\section{Discussion}

PHA is a liver tumor originating from endothelial and fibroblastic tissue, accounting for $0.1-2 \%$ of all primary liver malignancies [1]. Despite its rarity, PHA remains the most common malignant mesenchymal cell tumor of the liver [2]. PHA generally develops in the sixth to seventh decade of life and is predominantly found in males with a male-to-female ratio of 2-4:1 [11]. According to an epidemiological study from the United States, $25 \%$ of PHA were associated with known etiologies. Thorotrast application in angiography was linked to PHA in the past decade with the average latency period from exposure to onset of about 20 years. Vinyl chloride, in plastic fabrication, has also been shown to have an established association with PHA with the hazard ratio approximately 10- to 15-fold. Besides, other agents including arsenic androgen, anabolic steroids, cyclophosphamide, phenelzine, and copper are proposed as possible carcinogens $[2,9]$. However, these cases are rare and lack explicit associations.

The presentations of PHA are variable, ranging from asymptomatic to acute liver failure. Most of the patients have nonspecific symptoms that mimic chronic liver diseases, with late diagnosis as the consequence. These symptoms include abdominal pain, fatigue, weight loss, and anorexia [2]. The reported physical examinations of PHA comprised hepatosplenomegaly, jaundice, ascites, and rarely hepatic bruit due to its vascular nature. Few patients, approximately $9 \%$, present with symptoms secondary to metastasis. Hemoperitoneum is a fetal complication secondary to tumor rupture, which was reported in $17-27 \%[3,4]$.

Moreover, rare presentations of PHA in cases of acute liver failure, high-output heart failure, esophageal varices, hemothorax, and disseminated intravascular coagulopathy from Kasabach-Merritt syndrome have recently been reported [12].

For investigation, almost all patients (97\%) undergo a nonspecific abnormal liver function test. Accretion of ALP is the most common abnormal finding. Hyperbilirubinemia may occur in cases of advanced disease. Cytopenia is common in PHA, with 54\% of patients displaying thrombocytopenia. While anemia may reflect spontaneous tumor rupture or microangiopathic hemolytic anemia, there is no specific tumor marker corresponding to PHA [4].

The lack of specific clinical presentations and laboratory findings emphasizes the diagnostic value of radiological imaging. Conventional ultrasound has reported a limited yield in diagnostic evaluation. The mass typically demonstrated different echogenicity depending on necrosis or hemorrhage nature. 


\section{Case Reports in Gastroenterology} \begin{tabular}{l|l} 
Case Rep Gastroenterol 2020;14:137-149 \\
\hline DOI: 10.1159/000506928 & $\begin{array}{l}\text { @ 2020 The Author(s). Published by S. Karger AG, Basel } \\
\text { www.karger.com/crg }\end{array}$
\end{tabular}

Rujeerapaiboon and Wetwittayakhlang: Primary Hepatic Angiosarcoma: Varying Manifestations but Grave Prognosis

On imaging , similar findings appear on dynamic CT and magnetic resonance imaging (MRI). The dominant tumor usually showed heterogenous enhancement suggesting central necrosis, hemorrhage, and fibrotic change. Delayed progressive enhancement but incomplete venous and delayed phase of enhancing lesions is observed without a centripetal filling pattern. In comparison to hemangioma, the enhancing pattern of PHA is a peripheral rim with central septal-like or linear progression, while a hemangioma-enhancing pattern is centripetal nodular enhancement [5-7].

On T1-weighted MRI, the irregular high signal intensity of the dominant mass suggests the presence of hemorrhage. On T2-weighted images, there is increased signal intensity and a septum-like or rounded area of low intensity. The hyperintense signal indicates the area of hemorrhage or necrosis, while the hypointense signal represents hemosiderin deposition and fibrous solid portion. On dynamic contrast-enhanced MRI, the enhancement pattern shows the progressive enhancement of lesion as a dynamic CT scan [5-7].

Lastly, relevant angiographic findings comprise numerous mass lesions with fluffy staining and early pooling of contrast media that progressively increase over time. The most prevalent feature of the angiogram is intense peripheral stain late in the arterial phase.

The diagnosis of PHA remains problematic owing to lack of obvious clinical and investigation features, which are typically analogous with other vascular tumors. A definite diagnosis requires histopathology via liver biopsy. Many reports recommend open liver biopsy because of better visualization and easier hemostasis, whereas percutaneous biopsy, a simpler method, is a safer and faster procedure without significant complications [13]. Post-biopsy hemorrhage is the primary concern in PHA because of its vascularity. Bleeding occurrence was reported in $9 \%$, which can be managed by blood transfusion and hepatic arterial angioembolization.

Pathologically, PHA consists of four characteristics; multiple nodules, large dominant mass, mixed mass with nodule, and diffusely infiltrating micronodular tumor. The tumor has a pale white-yellow-gray color, a spongy appearance, and an ill-defined margin [3].

PHA is composed of pleomorphic atypical mesenchymal cells, polyhedral, and sometimes spindle-shaped [8]. Neoplastic cells contain prominent chromatin, atypical hyperchromic, and elongated nuclei with frequent mitoses. This tumor exhibits its own disorganized anastomosis vascular channels, ranging from dilated sinusoid or cavernous spaces to slit-like freely anastomosing vessels, formed by spindle-shaped cells [3]. Areas of necrosis, hemorrhage, and calcification are reported in $80 \%$ of specimens.

There are no specific immunochemistry markers. A recent report stated that the most sensitive and specific marker is ERG expression, with a 100\% sensitivity, followed by CD34 (87.5\%), CD31 (87.2\%), and factor VIII (41.7\%), respectively [8].

For the treatment of PHA, there is a paucity of effective therapeutic approaches. Surgical resection remains a promising treatment for PHA. Radiosurgery with R0 resection is the sole curative treatment. Adjuvant chemotherapy provides further survival benefit with reported median survival up to 17 months [10]. Liver transplantation is contraindicated in PHA owing to high recurrence and poor prognosis regardless of liver transplantation.

Chemotherapy is considered a palliative treatment in patients who are not surgical candidates. Many chemotherapy regimens have been demonstrated in various reports, none of which appear to be superior. Salvage chemotherapy with 5-fluorouracil/carboplatin/doxorubicin/ifosfamide improves survival in $50 \%$ of patients, based on its antiangiogenic properties. 
The limited efficacy of molecular treatment including bevacizumab, sorafenib, and sunitinib cannot be recommended. TACE is effective in patients with a dominant mass. Reports have shown that TACE with either lipiodol/cisplatin or lipiodol/mitomycin/Adriamycin is beneficial in $50 \%$ of patients $[14,15]$. Radiotherapy is not a treatment option for PHA due to the intrinsic radio-resistant property of tumor cells.

PHA carries a grave prognosis. Postdiagnosis median survival without treatment is approximately 1-6 months, with 3\% surviving longer than 2 years $[4,9,10]$. For patients who underwent surgical resection either with or without adjuvant chemotherapy, the median survival is approximately 17 months [10]. Curative surgery is difficult to perform in more than $80 \%$ of cases because of the advanced stage at diagnosis [4]. The most common cause of death is liver failure, accounting for $50 \%$ of cases, followed by hemoperitoneum from spontaneous tumor rupture $(25 \%)$. Other causes of death are metastasis disease, infection, renal failure, and heart failure (3\%) [4, 10]. Distant metastasis makes up more than $60 \%$ of cases, which are diagnosed post-mortem. The most common site of metastasis is the lungs, spleen, and bone, respectively. Complications are reported for $17-27 \%$ of individuals [4].

In conclusion, PHA is a rare, hepatic, and malignant tumor, which physicians may not recognize as it mimics other liver tumors resulting in late diagnosis. Clinical presentations are variable from mild to severe symptoms, and fetal complications may be present. Spontaneous tumor rupture or liver failure may commonly occur. Diagnosis of the disease in the early stage with CT or MRI and histopathology provides survival benefit. However, prognosis is still poor despite chemotherapy treatment.

\section{Acknowledgements}

The authors acknowledge Dr. Poowadon Wetwittayakhlung for providing histological pictures for these cases.

\section{Statement of Ethics}

Informed consent was obtained for this case series report. The names of the subjects are not mentioned in this case series, and no identifying image has been included for these cases.

\section{Disclosure Statement}

The authors have no conflicts of interest to declare.

\section{Funding Sources}

There are no funding sources to report. 


\section{Case Reports in Gastroenterology}

\section{Author Contributions}

N. Rujeerapaiboon wrote the manuscript, and P. Wetwittayakhlang wrote and supervised the writing of the manuscript and provided the clinical information of all cases. Both authors read and approved the final manuscript.

\section{References}

1 Mani H, Van Thiel DH. Mesenchymal tumors of the liver [viii.]. Clin Liver Dis. 2001 Feb;5(1):219-57.

2 Zhu YP, Chen YM, Matro E, Chen RB, Jiang ZN, Mou YP, et al. Primary hepatic angiosarcoma: A report of two cases and literature review. World J Gastroenterol. 2015 May;21(19):6088-96.

3 Chaudhary P, Bhadana U, Singh RA, Ahuja A. Primary hepatic angiosarcoma. Eur J Surg Oncol. 2015 Sep;41(9):1137-43.

4 Locker GY, Doroshow JH, Zwelling LA, Chabner BA. The clinical features of hepatic angiosarcoma: a report of four cases and a review of the English literature. Medicine (Baltimore). 1979 Jan;58(1):48-64.

5 Koyama T, Fletcher JG, Johnson CD, Kuo MS, Notohara K, Burgart LJ. Primary hepatic angiosarcoma: findings at CT and MR imaging. Radiology. 2002 Mar;222(3):667-73.

6 Pickhardt PJ, Kitchin D, Lubner MG, Ganeshan DM, Bhalla S, Covey AM. Primary hepatic angiosarcoma: multiinstitutional comprehensive cancer centre review of multiphasic CT and MR imaging in 35 patients. Eur Radiol. 2015 Feb;25(2):315-22.

7 Thapar S, Rastogi A, Ahuja A, Sarin S. Angiosarcoma of the liver: imaging of a rare salient entity. J Radiol Case Rep. 2014 Aug;8(8):24-32.

8 Wang ZB, Yuan J, Chen W, Wei LX. Transcription factor ERG is a specific and sensitive diagnostic marker for hepatic angiosarcoma. World J Gastroenterol. 2014 Apr;20(13):3672-9.

9 Timaran $\mathrm{CH}$, Grandas $\mathrm{OH}$, Bell JL. Hepatic angiosarcoma: long-term survival after complete surgical removal. Am Surg. 2000 Dec;66(12):1153-7.

10 Zheng YW, Zhang XW, Zhang JL, Hui ZZ, Du WJ, Li RM, et al. Primary hepatic angiosarcoma and potential treatment options. J Gastroenterol Hepatol. 2014 May;29(5):906-11.

11 Huang NC, Wann SR, Chang HT, Lin SL, Wang JS, Guo HR. Arsenic, vinyl chloride, viral hepatitis, and hepatic angiosarcoma: a hospital-based study and review of literature in Taiwan. BMC Gastroenterol. 2011 Dec;11(1):142.

12 Massarweh S, Munis A, Karabakhtsian R, Romond E, Moss J. Metastatic angiosarcoma and kasabach-merritt syndrome. Rare Tumors. 2014 Jun;6(2):5366.

13 Kang TW, Lee MW, Choi D, An C, Kim MJ, Joo I, et al. Safety of Percutaneous Biopsy for Hepatic Angiosarcoma: Results of a Multicenter Korean Survey. J Vasc Interv Radiol. 2016 Jun;27(6):846-51.

14 Ozden I, Bilge 0, Erkan M, Cevikbaș U, Acarli K. Five years and 4 months of recurrence-free survival in hepatic angiosarcoma. J Hepatobiliary Pancreat Surg. 2003;10(3):250-2.

15 Park YS, Kim JH, Kim KW, Lee IS, Yoon HK, Ko GY, et al. Primary hepatic angiosarcoma: imaging findings and palliative treatment with transcatheter arterial chemoembolization or embolization. Clin Radiol. 2009 Aug;64(8):779-85. 


\section{Case Reports in Gastroenterology}

Case Rep Gastroenterol 2020;14:137-149
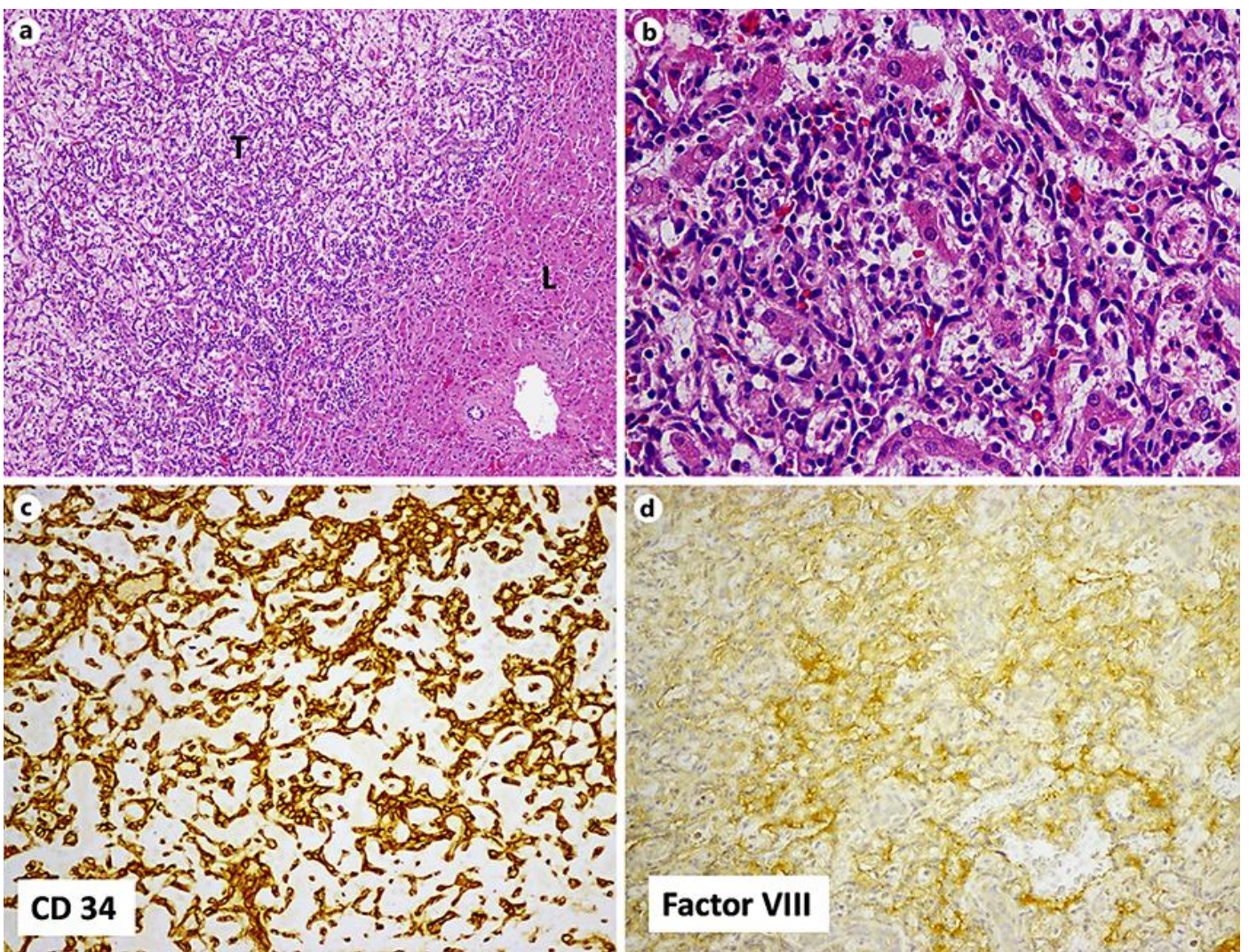

Fig. 1. Histopathological examination of tumor tissue in case 2. a Histopathological study (hematoxylineosin stain, $\times 40$ ) showed the tumor cells $(\mathrm{T})$ grow along sinusoids adjacent to hepatic cords (L). b The tumor cells appear abundant, poorly defined cell borders, pleomorphic with hyperchromatic nuclei. The abnormal vessels also showed enlarged endothelial cells with nuclear atypia $(\times 400)$. The Immunohistochemical study showed positive staining for CD 34 (c) and factor VIII (d). 


\section{Case Reports in Gastroenterology}

Case Rep Gastroenterol 2020;14:137-149

(C) 2020 The Author(s). Published by S. Karger AG, Basel DOI: $10.1159 / 000506928$ www.karger.com/crg

Rujeerapaiboon and Wetwittayakhlang: Primary Hepatic Angiosarcoma: Varying Manifestations but Grave Prognosis
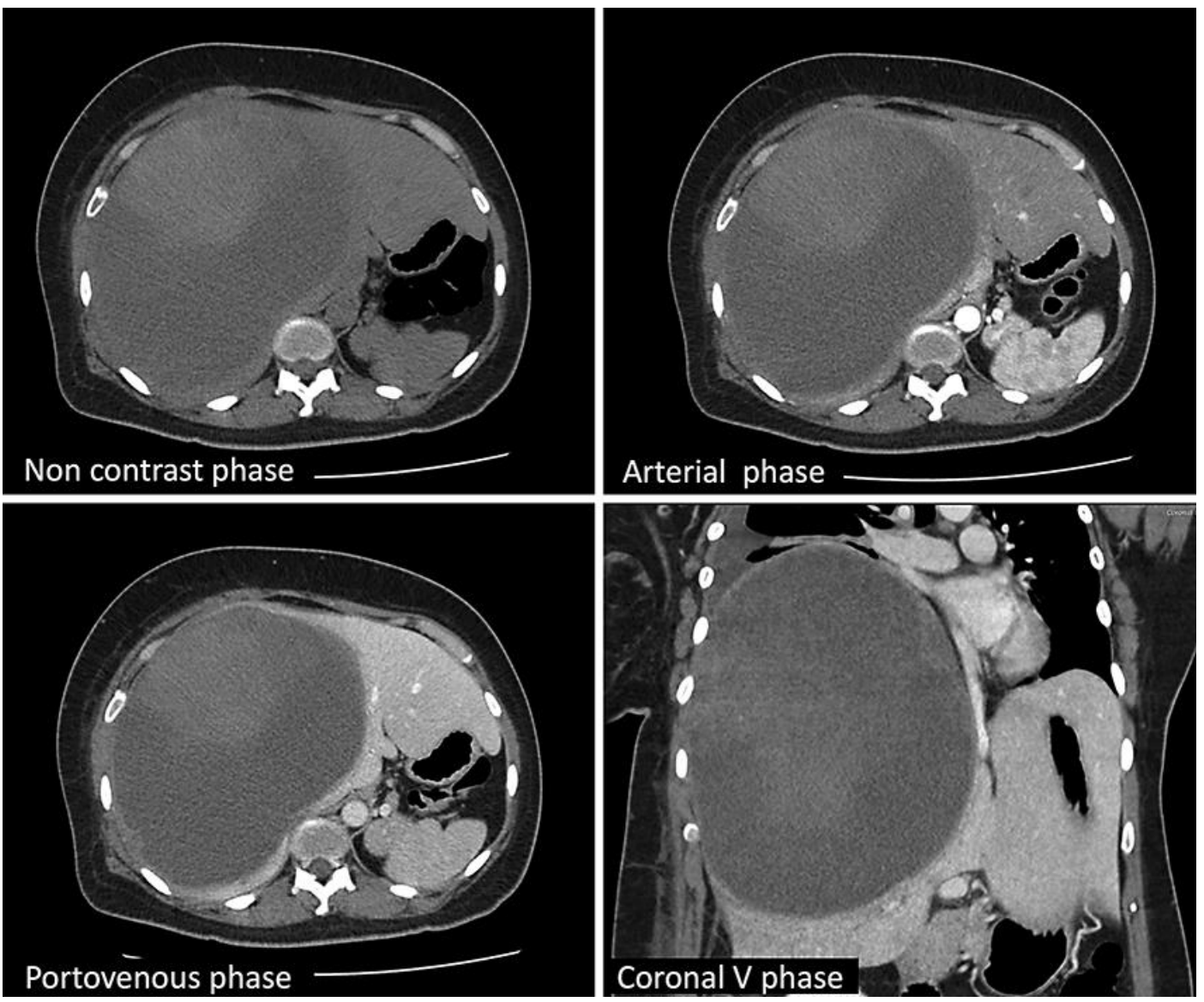

Fig. 2. Multiphase CT scan of liver in case 3 demonstrates a large hemorrhagic hepatic mass $15 \times 20 \times 23$ $\mathrm{cm}$ in size with an enhanced solid part at the anterosuperior part on plain phase. 


\section{Case Reports in Gastroenterology}

Case Rep Gastroenterol 2020;14:137-149
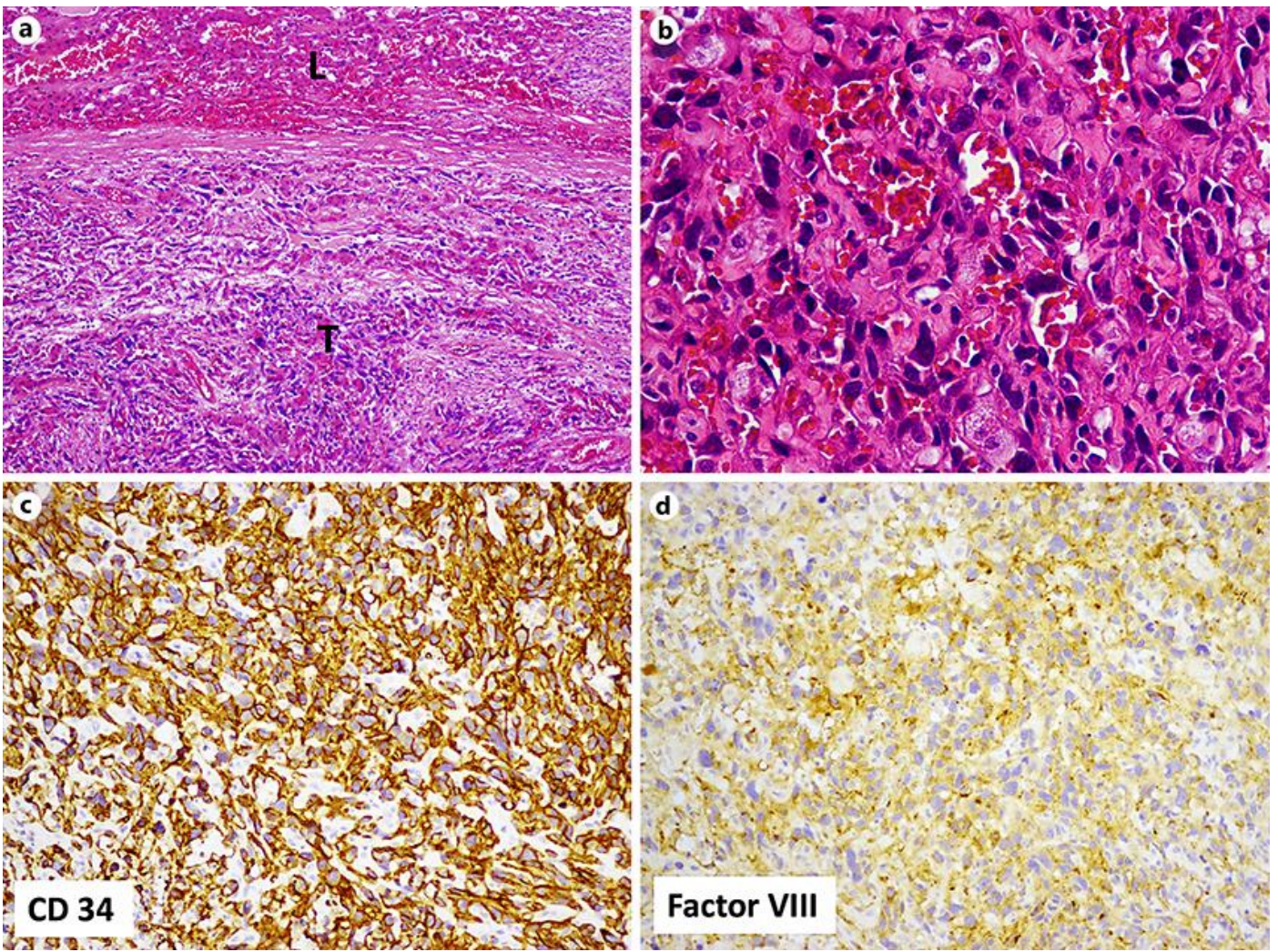

Fig. 3. Histopathological finding of primary hepatic angiosarcoma in case 3. a Histological examination of tumor tissue (hematoxylin-eosin stain, $\times 40$ ) showed an area of the tumor tissue (T) infiltrated in the liver tissue (L). $\mathbf{b}$ The tumor cells present diffuse proliferation of abnormal small vessels and enlargement of endothelial cells with nuclear atypia $(\times 400)$. The immunohistochemical study of the same tissue showed positive staining for CD 34 (c) and factor VIII marker (d), which indicated hepatic angiosarcoma. 


\section{Case Reports in Gastroenterology}

\begin{tabular}{l|l} 
Case Rep Gastroenterol 2020;14:137-149 \\
\hline DOI: 10.1159/000506928 & $\begin{array}{l}\text { (c) 2020 The Author(s). Published by S. Karger AG, Basel } \\
\text { www.karger.com/crg }\end{array}$
\end{tabular}

Rujeerapaiboon and Wetwittayakhlang: Primary Hepatic Angiosarcoma: Varying

Manifestations but Grave Prognosis
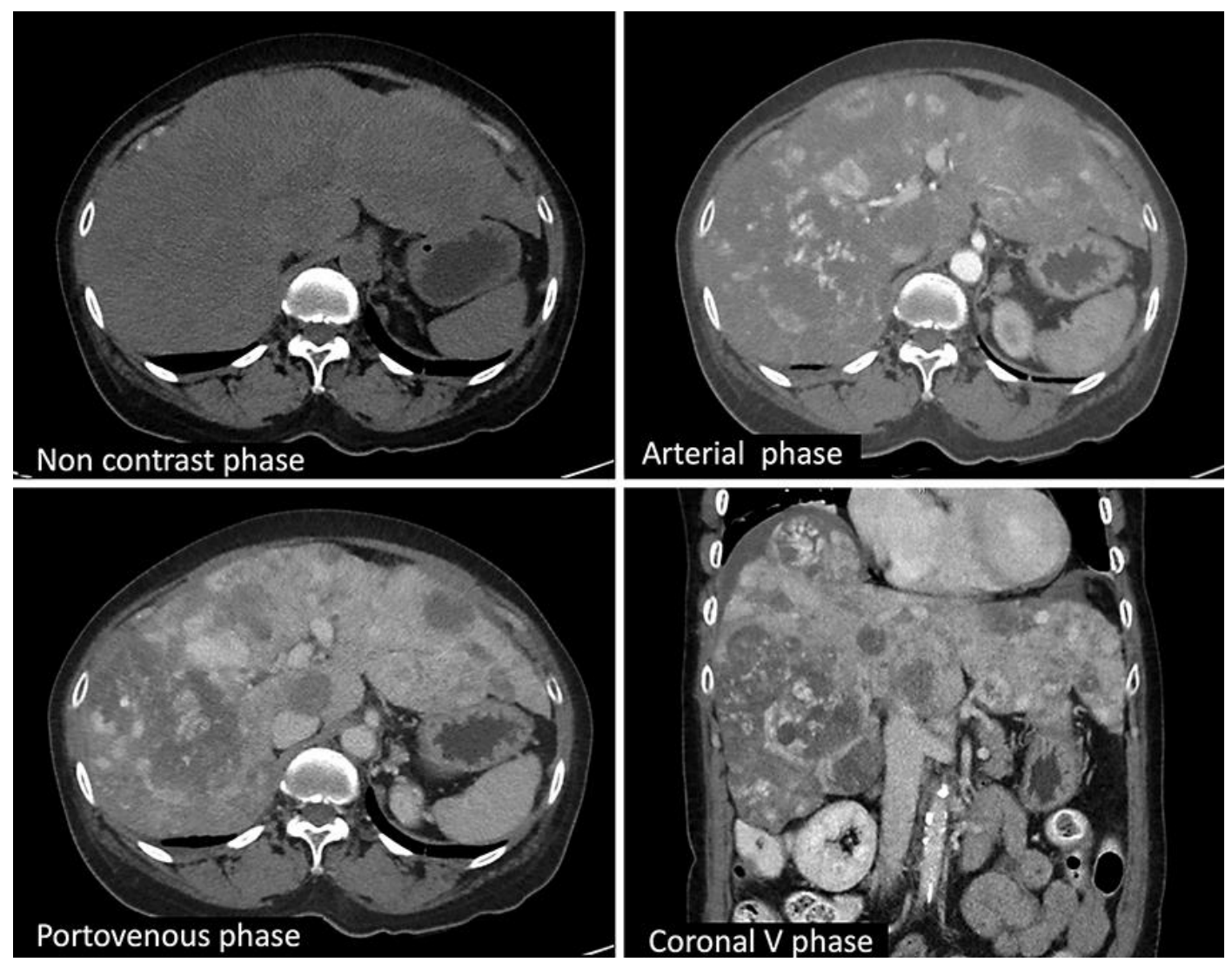

Fig. 4. Multiphase CT scan of the liver in case 4 illustrates multiple scattered hypervascular infiltrative masses and nodules, about 1-9 cm in size in an almost entire enlarged liver. The masses have progressive enhancement on portal venous phase, and most of them have surrounding ground-glass opacity which is a typical finding for hemorrhage in angiosarcoma. 
Gastroenterology

Rujeerapaiboon and Wetwittayakhlang: Primary Hepatic Angiosarcoma: Varying

Manifestations but Grave Prognosis

Table 1. Summary of clinical features, tumor characteristics, treatments, and survival outcomes in the four cases

\begin{tabular}{|c|c|c|c|c|c|c|c|c|}
\hline Case & $\begin{array}{l}\text { Age, } \\
\text { years }\end{array}$ & Sex & $\begin{array}{l}\text { Clinical } \\
\text { manifestations }\end{array}$ & $\begin{array}{l}\text { Tumor } \\
\text { characteristics }\end{array}$ & $\begin{array}{l}\text { Extrahepatic } \\
\text { metastasis }\end{array}$ & $\begin{array}{l}\text { Tumor } \\
\text { rupture }\end{array}$ & Treatment & $\begin{array}{l}\text { Survival } \\
\text { time from } \\
\text { symptom on- } \\
\text { set }\end{array}$ \\
\hline 1 & 81 & M & $\begin{array}{l}\text { massive upper GI } \\
\text { bleeding, ab- } \\
\text { dominal pain, jaun- } \\
\text { dice }\end{array}$ & $\begin{array}{l}\text { multiple infiltra- } \\
\text { tive mass }\end{array}$ & $\begin{array}{l}\text { spine, pleura, } \\
\text { stomach }\end{array}$ & no & $\begin{array}{l}\text { paclitaxel } \\
20 \% \text { dose re- } \\
\text { duction }\end{array}$ & 1.5 months \\
\hline 2 & 55 & $\mathrm{~F}$ & $\begin{array}{l}\text { abdominal pain, } \\
\text { jaundice, weight } \\
\text { loss }\end{array}$ & $\begin{array}{l}\text { multiple scattered } \\
\text { nodules }\end{array}$ & peritoneal & no & $\begin{array}{l}\text { paclitaxel } \\
20 \% \text { dose re- } \\
\text { duction }\end{array}$ & 19 months \\
\hline 3 & 47 & $\mathrm{~F}$ & $\begin{array}{l}\text { intraperitoneal } \\
\text { hemorrhage }\end{array}$ & $\begin{array}{l}\text { single dominant } \\
\text { mass with hemor- } \\
\text { rhage }\end{array}$ & none & yes & $\begin{array}{l}\text { surgical re- } \\
\text { section }\end{array}$ & 6 months \\
\hline 4 & 69 & $\mathrm{~F}$ & $\begin{array}{l}\text { abdominal pain, } \\
\text { weight loss, hepato- } \\
\text { megaly }\end{array}$ & $\begin{array}{l}\text { diffuse multiple } \\
\text { mass with hemor- } \\
\text { rhage }\end{array}$ & spine, lungs & yes & $\begin{array}{l}\text { best support- } \\
\text { ive care }\end{array}$ & 2 months \\
\hline
\end{tabular}

